\title{
Growth and Characterization of Indium Oxide, Zinc Oxide and Cadmium Sulfide Nanowires by Vapor-Liquid-Solid Growth Technique
}

\author{
Mojgan Mazouchi ${ }^{1}$, Shripriya Poduri ${ }^{1} \&$ Mitra Dutta $^{1}$ \\ ${ }^{1}$ University of Illinois at Chicago, Dept. of Electrical \& Computer Engineering, 1020 Sciences and Engineering \\ Offices (SEO), 851 South Morgan St. (M/C 154), Chicago, IL 60607, USA \\ Correspondence: Mojgan Mazouchi, University of Illinois at Chicago, Dept. of Electrical \& Computer \\ Engineering, 1020 Sciences and Engineering Offices (SEO), 851 South Morgan St. (M/C 154), Chicago, IL \\ 60607, USA.E-mail: mmazou2@uic.edu
}

\author{
Received: October 16, 2014 Accepted: October 24, 2014 Online Published: November 10, 2014 \\ doi:10.5539/apr.v6n6p55 \\ URL: http://dx.doi.org/10.5539/apr.v6n6p55
}

\begin{abstract}
In this study, the growth of three important semiconductor nanowires, Zinc Oxide, Indium Oxide and Cadmium Sulfide nanowires using the vapor-liquid-solid (VLS) method has been investigated. Different growth recipes with different growth parameters were incorporated to synthesize high quality and long NWs. It attempts to provide precise growth recipes which lead to high quality of nanowires. The effect of different growth conditions such as growth temperature, carrier gas flow, presence of metal catalyst and growth time has been investigated. Also, to evaluate the crystal quality of the nanowires, photoluminescence (PL) spectra of the as grown nanowires were investigated.
\end{abstract}

Keywords: Nanowires, Indium Oxide, Zinc Oxide, Cadmium sulfide (CdS), vapor liquid solid (VLS) growth

\section{Introduction}

For the growth and survival of the current integrated circuit industry, device scaling down to nanoscale device feature sizes has become a very important factor. Semiconductor industry has reached the regime where classical physics becomes invalid and the function of the device cannot be guaranteed with the further decrease in device dimensions (Fan, Werner, \& Zacharias, 2006). Hence, development of new technological concepts and materials are necessary because of the present concerns caused by device scaling. From this point of view, "bottom-up" approach is a promising solution. The bottom-up approach is a common technique to synthesize the NW structures. In this method use of a metal catalyst has enabled the routine fabrication of sophisticated one-dimensional structures and devices that is otherwise not possible with conventional top-down approaches. This growth technique most frequently used is the vapor-liquid-solid (VLS) mechanism. VLS method was introduced by Wagner and Ellis with the growth of silicon whiskers (Wagner \& Ellis, 1964). Other techniques used for NWs growth include chemical vapor deposition (CVD), laser ablation, supercritical fluid solution phase, metalorganic chemical vapor deposition (MOCVD), chemical beam epitaxy (CBE) and molecular beam epitaxy (MBE) (Fortuna \& Li, 2010). However, among the different growth techniques the VLS method has proven to be extremely flexible and allows for the controlled growth of complex nanostructures. For example, hetero-junctions can be formed axially along the nanowire simply by changing the material precursors present in the reaction environment (Fortuna \& Li, 2010).

Semiconductor NWs have a wide range of applications in diodes, field effect transistors, optoelectronic devices, sensors, thermoelectrical devices, photocatalysis, and piezoelectronics. NW structures exhibit unique and superior properties compared to their bulk counterparts, properties in which their one-dimensional (1D) confined transport of electrons, large surface to volume ratio, quantum confinement, useful for optoelectronic devices, and excellent mechanical properties play key roles. Among the semiconductor NWs the wide variety of electronic and chemical properties of metal oxide semiconductor NWs makes them exciting materials for basic research and for technological applications alike. Oxides span a wide range of electrical properties from wide band-gap insulators to metallic and superconducting. Recently, much research has focused on the fabrication of semiconducting oxide nanowires with wide band-gaps. Of these, Zinc Oxide $(\mathrm{ZnO})$ nanowires have been 
extensively studied for potential applications in optoelectronic, photo-detectors, and high sensitivity sensors (Purahmad, Stroscio, \& Dutta, 2014; Zhai et al., 2009) and piezoelectric energy harvesting (Purahmad, Stroscio, \& Dutta, 2013). $\mathrm{ZnO}$ is a wide band-gap (about $3.4 \mathrm{eV}$ ) semiconductor with high exiction binding energy of (60 $\mathrm{meV}$ ) and the combination of $\mathrm{ZnO}$ large electromechanical coupling with non-central symmetry of its wurtzite crystal structure brings up its strong piezoelectric and pyroelectrical properties (Purahmad, Stroscio, \& Dutta, 2013; $\mathrm{Xu}, 2014)$. Not much work has been done with Indium Oxide $\left(\mathrm{In}_{2} \mathrm{O}_{3}\right)$ which is also a wide band gap semiconductor (direct band gap of 3.5-3.7 eV) (Fechete, Wlodarski, Holland, \& Kalantar-zadeh, 2006; Singh, Zhang, \& Lee, 2009). It is more used as the significant transparent conducting oxide (TCO) material optoelectronic applications such as flat panel display, solar cells and organic light-emitting diodes (Fechete, Wlodarski, Holland, \& Kalantar-zadeh, 2006; Singh, Zhang, \& Lee, 2009). Cadmium sulfide (CdS) is a direct band gap (about $2.4 \mathrm{eV}$ ) semiconductor (Poduri, Dutta, \& Stroscio, 2014) having excellent electron transport properties which makes it suitable for many optoelectronic devices. CdS based nanoscale devices are being used widely for a range of applications such as photo-detectors (Gao, Li, \& Wang, 2005), photovoltaic cells (Kang, \& Kim, 2006), and lasers (Duan, Huang, Agarwal, \& Lieber, 2003). In this work, $\mathrm{ZnO}$ and $\mathrm{In}_{2} \mathrm{O}_{3}$ were grown on silicon substrates coated with $5 \mathrm{~nm}$ gold as catalyst through vapor-liquid-solid mechanism (VLS). CdS nanowires were also grown by VLS technique on ITO coated glass substrate with sputtered Au nano-clusters as catalyst. Photoluminescence (PL) studies were also performed on as grown ZnO NWs and CdS NWs to probe electronic and crystalline properties of these grown nanowires.

\section{Experimental Details}

The nanowires were grown by the vapor liquid solid (VLS) method inside a 2 inches diameter of a horizontal quartz tube at atmospheric pressure. Silicon wafers (n-type, 100 plane) was used as substrate for the nanowire growth. Prior to the growth, the samples were cleaned by acetone and dried by $\mathrm{N}_{2}$ steam, then were coated with a layer of $\mathrm{Au}$ thin film $(5 \mathrm{~nm})$ using e-beam evaporation. The source consisted of zinc oxide and indium oxide powders (99.99\%, Aldrich Company) mixed with graphite in a weight ratio of 1:1 for $\mathrm{ZnO}$ and $4: 1$ for $\mathrm{In}_{2} \mathrm{O}_{3}$ to carry out a carbothermal reaction process. The coated substrates and ceramic boat with metal oxide powder and graphite powder were placed in the middle of a 2 inches quartz tube. The system was heated to $900{ }^{\circ} \mathrm{C}$ with a constant flow (350 sccm) of Ar as carrier gas for $30 \mathrm{~min}$ and then cooled down to room temperature. Schematic diagram and VLS experimental growth setup are shown in Figure 1.
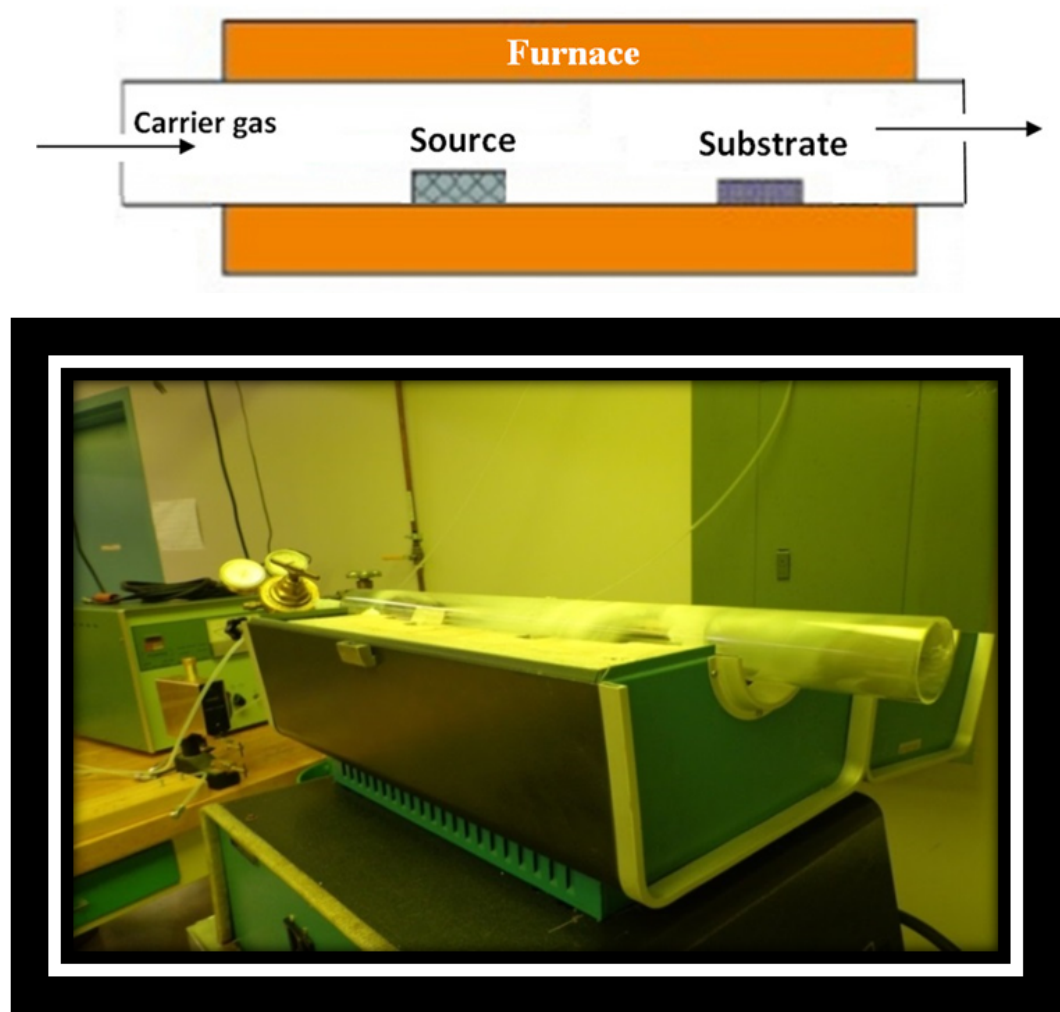

Figure 1. The schematic diagram and experimental growth set up 
CdS nanowires were synthesized using catalyst assisted VLS growth mechanism. CdS nanowires were grown on Indium Tin Oxide (ITO) coated glass substrate using gold $(\mathrm{Au})$ nanoclusters as catalyst. For VLS growth of nanowires, the ITO coated glass substrate were cleaned with soap water and rinsed in deionized (DI) water. After rinsing off these substrates in DI water, these ITO coated glass were ultrasonicated in acetone and isopropanol for 30 min followed by drying in nitrogen stream. Au of $5 \mathrm{~nm}$ thickness was sputtered on these cleaned ITO glass substrate for its use as catalyst to assist the VLS growth of nanowires. The CdS nanowires were synthesized using a dual zone quartz tube furnace heating instrument. CdS powder (99.99 \%, Sigma Aldrich Company) of $0.8 \mathrm{~g}$ in weight was used as source. The ceramic boat having CdS powder was placed in one heating zone and the ITO glass substrate with gold nanoclusters in the second heating zone. $5 \%$ hydrogen with $95 \%$ Argon gas was used as the carrier gas with a constant flow rate of $100 \mathrm{sccm}$. The source was kept in one zone and sample in other zone of the dual zone tube furnace. The source and sample were heated to 900 and $580^{\circ} \mathrm{C}$, respectively for $1 \mathrm{~h}$ (Poduri, Dutta, \& Stroscio, 2014).

Finally, scanning electron microscopy imaging was performed to study the morphology and ascertain the growth of nanowires. Photoluminescence spectral studies were also employed to investigate the electronic states and crystal structure of the VLS grown $\mathrm{ZnO}$, and CdS nanowires.

\section{Results and Discussion}

The VLS nanowire growth mechanism starts with the dissolution of gaseous reactants in nano-sized liquid droplets of the catalyst metal and it is followed by nucleation and growth of single-crystalline wires or rods. It is reported in Yang (2005) that the diameter of a NW is dependent on the alloy droplet size and starting metal seed. In this experiment of VLS growth, the metal nanoclusters like Au which acts as a catalyst on the forms a liquid/solid interface on heating. The source material vapor enters the nano-sized liquid droplets of the catalyst metal to become supersaturated resulting in $\mathrm{ZnO} / \mathrm{In}_{2} \mathrm{O}_{3} / \mathrm{CdS}$ nucleation underneath the liquid metal particle and thus forming a nanowire.

In case of $\mathrm{ZnO}$, the carbothermal reaction process can be expressed as following:

carbothermal reduction:

$$
\mathrm{ZnO}(\mathrm{s})+\mathrm{C}(\mathrm{s})=\mathrm{Zn}(\mathrm{v})+\mathrm{CO}(\mathrm{g})
$$

Catalyst alloy formation can be described by:

$$
\mathrm{Zn}(\mathrm{v})+\mathrm{Au}(\mathrm{s})=\mathrm{AuZn}(\mathrm{l})
$$

The NW formation can be explained by the following reaction:

$$
\operatorname{AuZn}(1)+\mathrm{Zn}(\mathrm{v})+1 / 2 \mathrm{O}_{2}=\mathrm{AuZn}(\mathrm{l})+\mathrm{ZnO}(\mathrm{s})
$$

In case of $\operatorname{In}_{2} \mathrm{O}_{3}$, the carbothermal reaction process can be explained as follow (Singh, Zhang, \& Lee, 2009):

$$
\mathrm{In}_{2} \mathrm{O}_{3}(\mathrm{~s})+3 \mathrm{C}(\mathrm{s})=2 \operatorname{In}(\mathrm{v})+3 \mathrm{CO}(\mathrm{v})
$$

In order to form $\operatorname{In}_{2} \mathrm{O}_{3}$ nanowires, the metal (In) vapor gets oxidized as follow:

Catalyst alloy formation can be described by:

$$
2 \operatorname{In}(\mathrm{v})+2 \mathrm{Au}(\mathrm{s})=2 \mathrm{AuIn}(\mathrm{l})
$$

In order to form $\operatorname{In}_{2} \mathrm{O}_{3}$ nanowires, the metal (In) vapor gets oxidized:

$$
2 \mathrm{AuIn}(\mathrm{l})+4 \mathrm{In}(\mathrm{v})+3 \mathrm{O}_{2}(\mathrm{~g})=2 \mathrm{AuIn}(\mathrm{l})+2 \operatorname{In}_{2} \mathrm{O}_{3}(\mathrm{~s})
$$

In case of CdS, the VLS growth equations are explained as follows:

$$
\mathrm{CdS}+\mathrm{H}_{2}=\mathrm{Cd}(\mathrm{v})+\mathrm{H}_{2} \mathrm{~S}(\mathrm{v})
$$

Catalyst alloy formation can be described by:

$$
\mathrm{Cd}(\mathrm{v})+\mathrm{Au}(\mathrm{s})=\mathrm{AuCd}(\mathrm{l})
$$

The NW formation can be explained by the following reaction:

$$
\mathrm{AuCd}(\mathrm{l})+\mathrm{Cd}(\mathrm{v})+\mathrm{H}_{2} \mathrm{~S}(\mathrm{v})=\mathrm{AuCd}(\mathrm{l})+\mathrm{CdS}(\mathrm{s})+\mathrm{H}_{2}(\mathrm{v})
$$

The as-grown $\mathrm{ZnO}$ nanowires and $\mathrm{In}_{2} \mathrm{O}_{3}$ were characterized with a variable-pressure Hitachi S-3000N scanning electron microscope (SEM). The CdS nanowires were examined under JEOL 7500 SEM and also EDS was performed to know the elemental composition. The SEM images of as grown $\mathrm{ZnO}$ NWs under an inappropriate and an appropriate growth condition are shown in Figure 2 where Figure 2 ( $a, b$ and $c$ ) are showing the top view, side view and randomly grown $\mathrm{ZnO}$ NWs, respectively.. Another important parameter which may result in 
uniform growth of NWs or a random growth is the flow of carrier gases. The effect of this parameter can be seen in Figure 2 (c). The as-grown $\mathrm{ZnO}$ NWs have an average length about $20 \mu \mathrm{m}$ and a diameter in range of 50 to $200 \mathrm{~nm}$. The average length of as grown $\mathrm{ZnO}$ NWs is higher than other methods such as RF sputtering techniques (Ranwa, Kulriya, Dixit, \& Kumar, 2014) which used to grow the self-aligned ZnO nanorods.
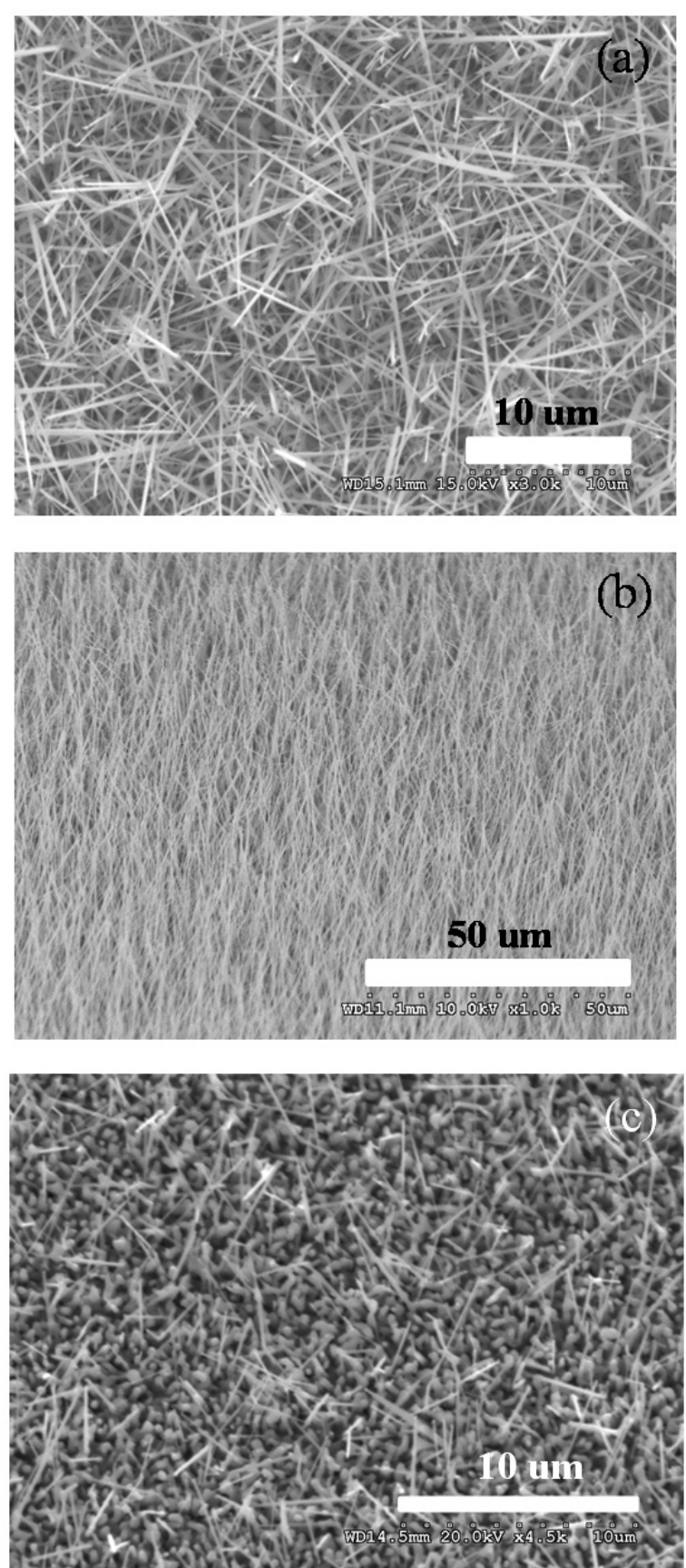

Figure 2. SEM image of as grown $\mathrm{ZnO}$ NWs (a and b) under an appropriate growth condition and (c) under an inappropriate growth condition

The SEM images of as grown $\operatorname{In}_{2} \mathrm{O}_{3}$ NWs are shown in Figure 3 where Figure 3 ( $a, b$ and $c$ ) are showing the top view, side view and randomly grown $\operatorname{In}_{2} \mathrm{O}_{3} \mathrm{NWs}$, respectively. Comparing with the straight $\mathrm{ZnO}$ NWs shown in Figure 2, Figure 3(a) and Figure 3(b) shows branched nanowires which are connected by several junctions and resulting in a network of the nanowires. In case of $\operatorname{In}_{2} \mathrm{O}_{3} \mathrm{NWs}$, It is also well known that the diameter of the nanowires is determined by the size of the alloy droplet, which in turn is determined by the original Au cluster 
size (Huang et al., 2001). Figure 3 (c) represents randomly oriented $\operatorname{In}_{2} \mathrm{O}_{3}$ NWs and non-uniform layered stacking structures due to the inappropriate growth condition that were used.
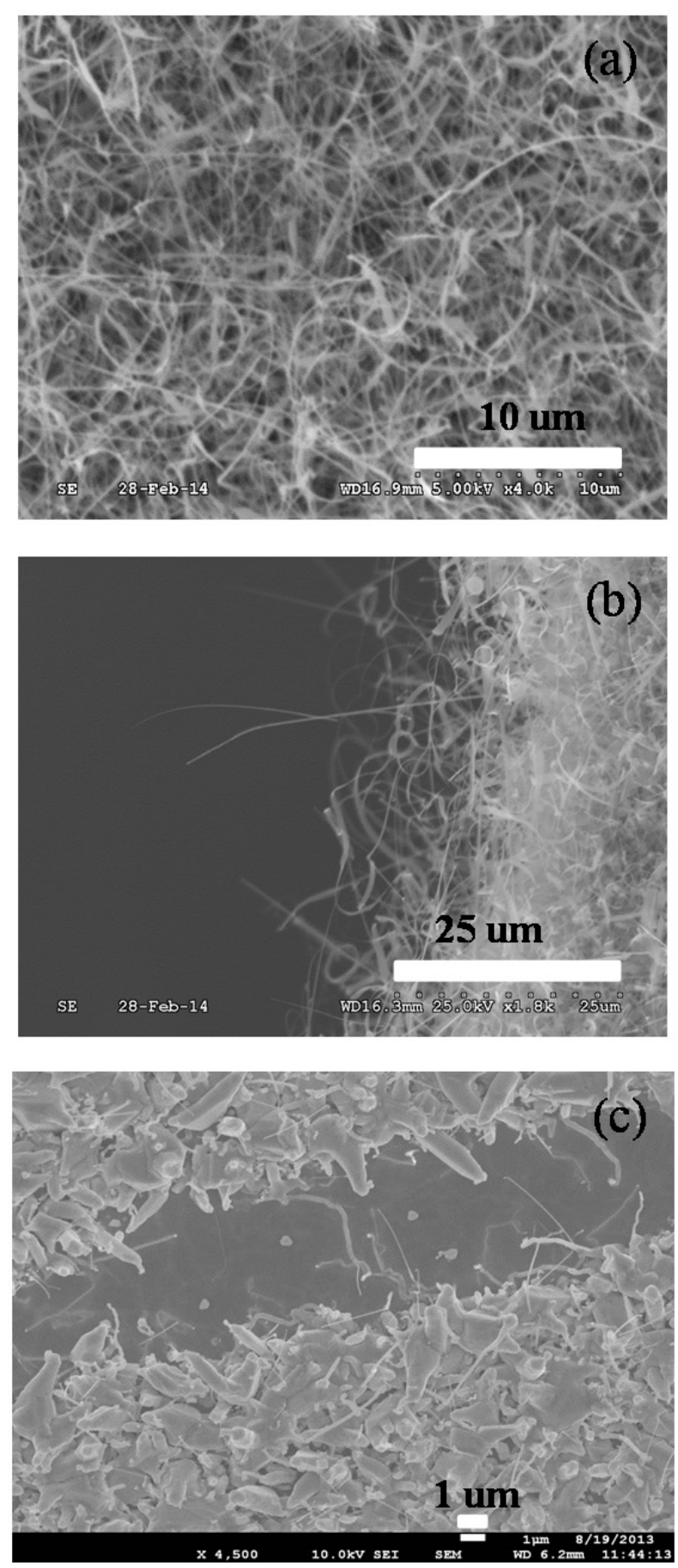

Figure 3. SEM image of the grown $\operatorname{In}_{2} \mathrm{O}_{3} \mathrm{NWs}$ ( $\mathrm{a}$ and $\mathrm{b}$ ) under an appropriate growth condition and (c) under an inappropriate growth condition

The SEM images of the as grown CdS nanowires by VLS growth under appropriate and inappropriate growth conditions are shown in Figure 4. The temperature of the source material was only $500{ }^{\circ} \mathrm{C}$ and the carrier gas flow rate was $500 \mathrm{sccm}$ for the growth of CdS nanowires which is shown in Figure 4 (c). However, the temperature of $500{ }^{\circ} \mathrm{C}$ was not appropriate and also the gas flow rate of $500 \mathrm{sccm}$ was very high for the growth of CdS naowires. 

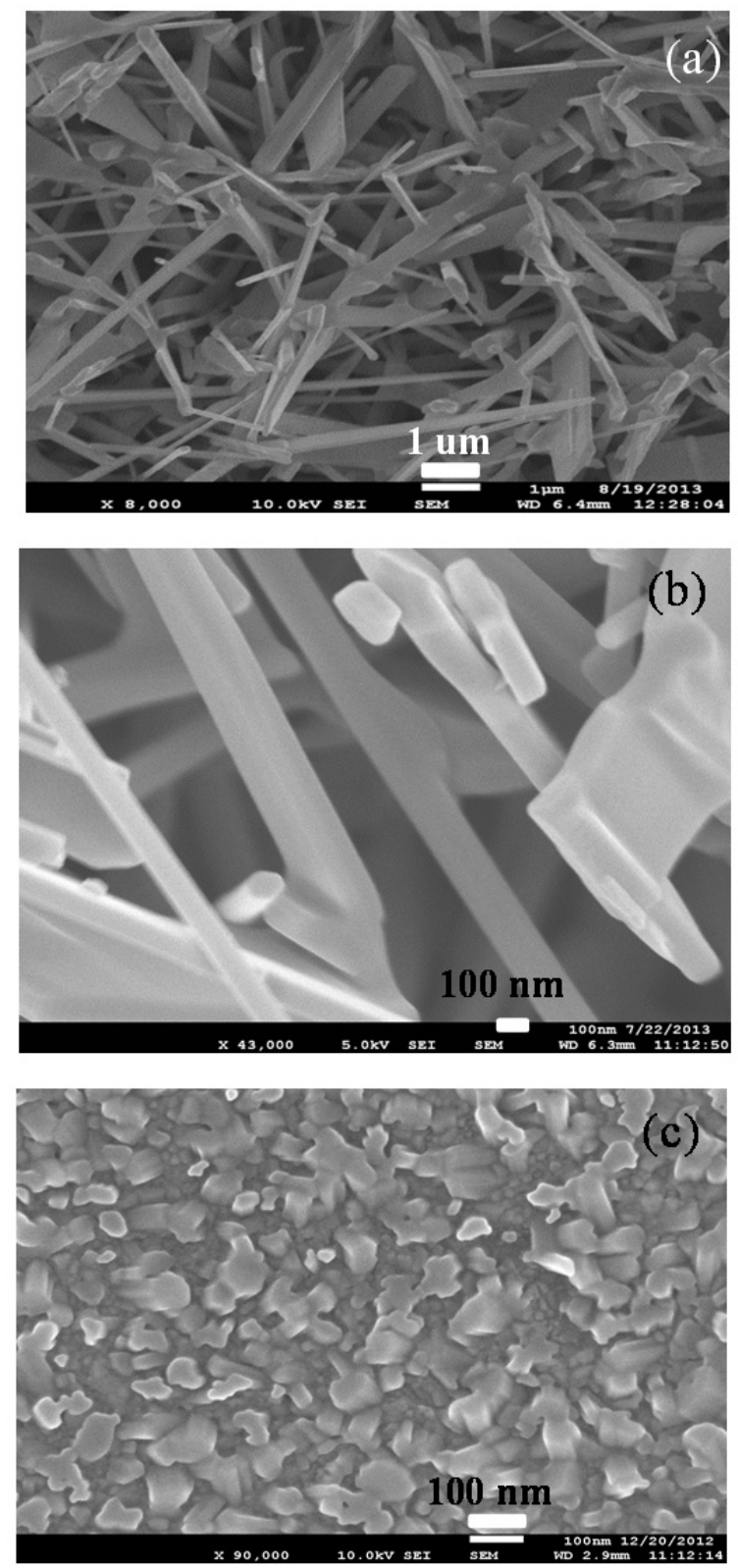

Figure 4. SEM image of the grown CdS NWs ( $a$ and b) under an appropriate growth condition and (c) under an inappropriate growth condition

To summarize, the appropriate growth parameters for these nanowires are tabulated in Table 1 as follows:

Table 1. Appropriate growth parameters for VLS growth

\begin{tabular}{ccccccccc}
\hline Nanowire & Catalyst & Substrate & Carrier Gas & sccm flow & Powder source & Powder Source Temperature & Sample Temperature & Time \\
\hline $\mathrm{ZnO}$ & $5 \mathrm{~nm} \mathrm{Au}$ & $\mathrm{Si}$ & $\mathrm{Ar}$ & 350 & Graphite : $\mathrm{ZnO} 1: 1$ & $900^{\circ} \mathrm{C}$ & $900^{\circ} \mathrm{C}$ & $0.5 \mathrm{hr}$ \\
$\mathrm{In}_{2} \mathrm{O}_{3}$ & $5 \mathrm{~nm} \mathrm{Au}$ & $\mathrm{Si}$ & $\mathrm{Ar}$ & 350 & Graphite: $\mathrm{In}_{2} \mathrm{O}_{3} 1: 4$ & $900^{\circ} \mathrm{C}$ & $900^{\circ} \mathrm{C}$ & $0.5 \mathrm{hr}$ \\
$\mathrm{CdS}$ & $5 \mathrm{~nm} \mathrm{Au}$ & ITO-glass & $5 \% \mathrm{H}_{2}+95 \% \mathrm{Ar}$ & 100 & $\mathrm{CdS}$ & $900^{\circ} \mathrm{C}$ & $580^{\circ} \mathrm{C}$ & $1 \mathrm{hr}$ \\
\hline
\end{tabular}

Furthermore, to analyse the elemental composition of CdS grown samples, Energy Dispersive X-ray Spectroscopy (EDS) were performed. The EDS result for the VLS grown nanowires are shown in Figure 5. Figure 5 shows that the $\mathrm{Cd}, \mathrm{S}$ are present in the sample confirming the growth of $\mathrm{CdS}$ nanowires In and $\mathrm{O}$ are 
due to the ITO coating on the glass. Si is probably present which can be due to the presence of some dust particles.

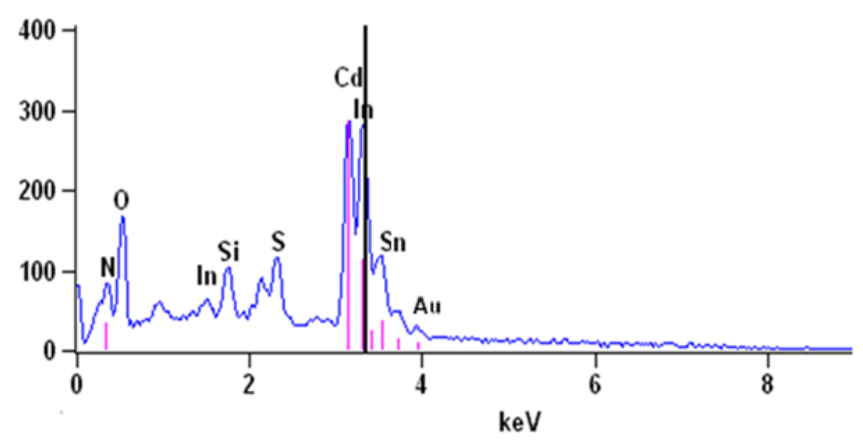

Figure 5. EDS result for VLS grown CdS nanowires

Photoluminescence (PL) spectral experiments were performed to probe the electronic and optical properties of these nanowires. The photoluminescence characteristics of the grown $\mathrm{CdS}, \mathrm{ZnO}$ and $\mathrm{In}_{2} \mathrm{O}_{3}$ nanowires were investigated using a He-Cd laser of wavelength $325 \mathrm{~nm}$ for excitation at room temperature. The PL emission peak was observed for VLS grown CdS nanowires was at $510 \mathrm{~nm}(2.43 \mathrm{eV}), 382 \mathrm{~nm}(\sim 3.3 \mathrm{eV})$ for $\mathrm{ZnO}$ and 381 $\mathrm{nm}(\sim 3.4 \mathrm{eV})$ for $\mathrm{In}_{2} \mathrm{O}_{3}$ nanowires as shown in Figure 6, Figure 7 and Figure 8.

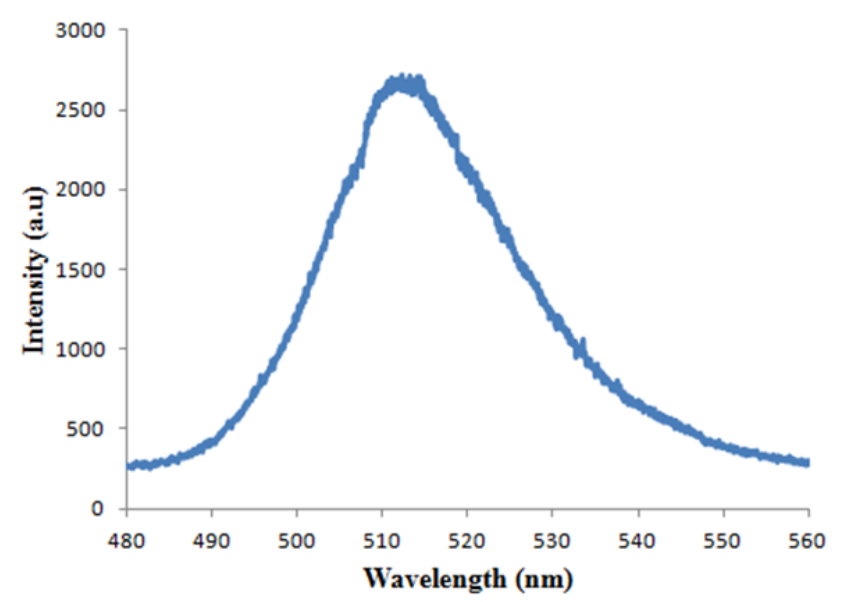

Figure 6. PL spectra for VLS grown CdS nanowires with peak at $510 \mathrm{~nm}$

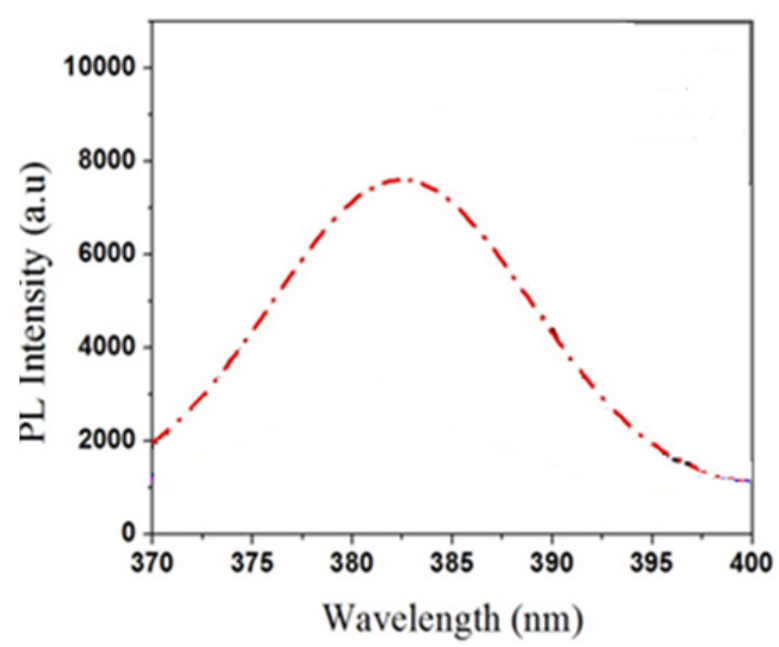

Figure 7. PL spectra for VLS grown $\mathrm{ZnO}$ nanowires with peak at $382 \mathrm{~nm}$. 


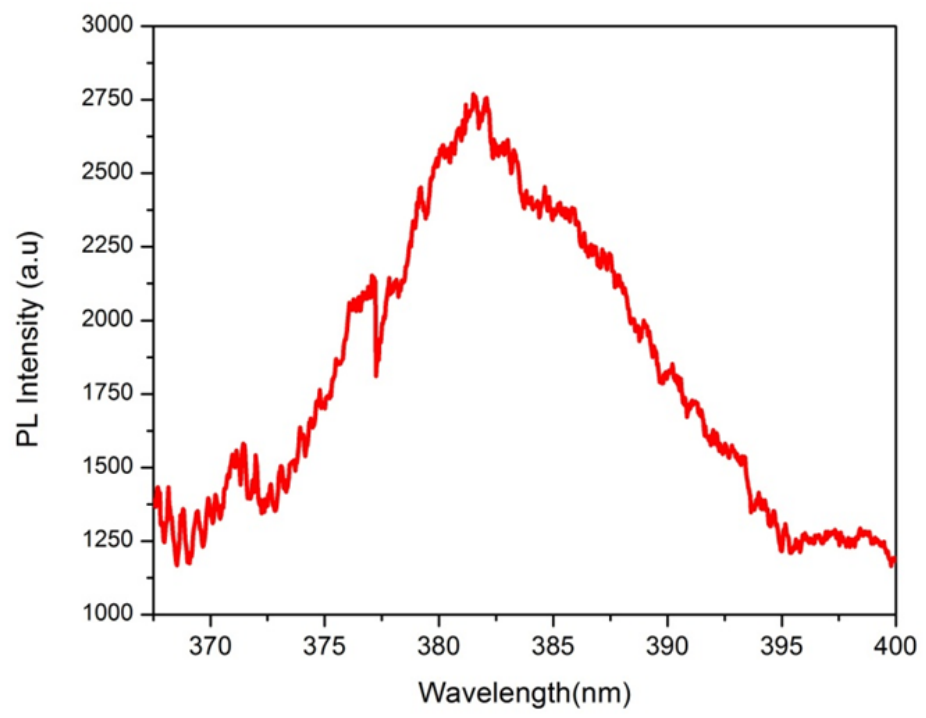

Figure 8. PL spectra for VLS grown $\mathrm{In}_{2} \mathrm{O}_{3}$ nanowires

The PL emission energy observed for CdS nanowires is close to the band gap energy of CdS (Poduri, Dutta, \& Stroscio, 2014). The PL spectrum of both $\mathrm{CdS}, \mathrm{ZnO}$ and $\mathrm{In}_{2} \mathrm{O}_{3}$ nanowires show good quality of the nanowires and PL peak is very much in accordance with the band gap of the material.A detailed study on PL spectra of as grown ZnO NWs is also reported some where else (Purahmad, Stroscio, \& Dutta, 2014).

\section{Summary}

In summary, we have demonstrated the synthesis of high quality $\mathrm{ZnO}, \mathrm{CdS}$ and $\mathrm{In}_{2} \mathrm{O}_{3}$ and nanostructures in the forms of nanowires and branched structures using VLS method. The VLS growth mechanism of ZnO, CdS NWs and $\mathrm{In}_{2} \mathrm{O}_{3} \mathrm{NWs}$ with different growth parameters was investigated and it was shown that the ideal growth condition is a function of type of material which is grown. It has been seen that the VLS growth is also dependent on all the parameters such as the size of the seed catalyst, gas flow rate, time and temperature.

\section{References}

Duan, X., Huang, Y., Agarwal, R., \& Lieber, C. M. (2003). Single-nanowire electrically driven lasers. Nature, 421(6920), 241-245. http://dx.doi.org/10.1038/nature01353

Fan, H. J., Werner, P., \& Zacharias, M. (2006). Semiconductor Nanowires, From Self-Organization to Patterned Growth. J. small., 2(6), 700 - 717. http://dx.doi.org/10.1002/smll.200500495

Fechete, A. C., Wlodarski, W., Holland, A. S., \& Kalantar-zadeh, K. (2006). Growth of Indium Oxide Nanostructures by Thermal Evaporation. Nanoscience. Nanothechnology, ICONN conference.

Fortuna, S. A., \& Li, X. (2010). Metal-catalyzed semiconductor nanowires: a review on the control of growth directions. Semiconductor Science and Technology, 25(2), 024005. http://dx.doi.org/10.1088/0268-1242/ 25/2/024005

Gao, T., Li, Q. H., \& Wang, T. H. (2005). CdS nanobelts as photoconductors. Applied Physics Letters, 86(17), 173105. http://dx.doi.org/10.1063/1.1915514

Huang, M. H., Wu, Y., Feick, H., Tran, N., Weber, E., \& Yang, P. (2001). Catalytic growth of zinc oxide nanowires by vapor transport. Advanced Materials, 13(2), 113-116. http://dx.doi.org/10.1002/1521-4095 (200101)13:2<113::AID-ADMA113>3.0.CO;2-H

Kang, Y., \& Kim, D. (2006). Well-aligned CdS nanorod/conjugated polymer solar cells. Solar energy materials and solar cells, 90(2), 166-174. http://dx.doi.org/10.1016/j.solmat.2005.03.001

Poduri, S. Dutta, M., \& Stroscio, M. (2014). Growth and Characterization of CdS nanowires on ITO coated glass substrate. 2014 International Conference of Material Science and Material Engineering (MSME 2014). 
Poduri, S., Dutta, M., \& Stroscio, M. (2014). Characterization of CdS Nanowires Self-Assembled in a Nanoporous Alumina Template. Journal of Electronic Materials, 43(11), 3979-3983. http://dx.doi.org/10.1007/s11664-014-3305-0

Purahmad, M., Stroscio, M. A., \& Dutta, M. (2013). A theoretical study on the effect of piezoelectric charges on the surface potential and surface depletion region of $\mathrm{ZnO}$ nanowires. Semiconductor Science and Technology, 28(1), 015019. http://dx.doi.org/10.1088/0268-1242/28/1/015019

Purahmad, M., Stroscio, M. A., \& Dutta, M. (2014). Strong Enhancement of Near-Band-Edge Photoluminescence of ZnO Nanowires Decorated with Sputtered Metallic Nanoparticles. Journal of Electronic Materials, 43(3), 740-745. http://dx.doi.org/10.1007/s11664-013-2924-1

Ranwa, S., Kulriya, P. K., Dixit, V., \& Kumar, M. (2014). Temperature dependent electrical transport studies of self-aligned $\mathrm{ZnO}$ nanorods/Si heterostructures deposited by sputtering. Journal of Applied Physics, 115(23), 233706. http://dx.doi.org/10.1063/1.4883961

Singh, N., Zhang, T., \& Lee, P. S. (2009). The temperature-controlled growth of In2O3 nanowires, nanotowers and ultra-long layered nanorods. Nanotechnology, 20(19), 195605. http://dx.doi.org/10.1088/0957-4484/ 20/19/195605

Wagner, R. S., \& Ellis, W. C. (1964). Vapor-liquid-solid mechanism of single crystal growth. Appl. Phys. Lett., 4, 89-90. http://dx.doi.org/10.1063/1.1753975

$\mathrm{Xu}, \mathrm{K}$. (2014). Design and Applications of Nanomaterials for Sensors. Challenges and Advances in Computational Chemistry and Physics, 16, 61-97.

Yang, P. (2005). The chemistry and physics of semiconductor nanowires. MRS bulletin, 30(02), 85-91. http://dx.doi.org/10.1557/mrs2005.26

Zhai, T., Fang, X., Liao, M., Xu, X., Zeng, H., Yoshio, B., \& Golberg, D. (2009). A comprehensive review of one-dimensional metal-oxide nanostructure photodetectors. Sensors, 9(8), 6504-6529. http://dx.doi.org/10. $3390 /$ s90806504

\section{Copyrights}

Copyright for this article is retained by the author(s), with first publication rights granted to the journal.

This is an open-access article distributed under the terms and conditions of the Creative Commons Attribution license (http://creativecommons.org/licenses/by/3.0/). 